\title{
A PÓLIS, O TIRANO, O SANTUÁRIO: O USO DO CULTO POLÍADE COMO ESTRATÉGIA DE LEGITIMAÇÃO EM SAMOS ${ }^{1}$
}

\begin{abstract}
ALINE PORFIRIO ${ }^{2}$
Resumo: Entre 532 e 522 a.C., Samos foi governada por Polícrates, um tirano. Por se tratar de um governo ilegítimo, sem base e apoio da aristocracia local, foi necessário então criar uma base de poder para legitimar seu governo. Para tanto, o tirano sâmio se vale de um extenso programa de construção e reformas de caráter monumental, cujo desenvolvimento este artigo pretende elucidar.

Palavras-chave: Samos; Polícrates; Tirania; Hera; Santuário.

1 INTRODUÇÃO

Uma das formas mais interessantes de entender a materialidade é vê-la como uma forma de expressão política, econômica e religiosa. Esses elementos se potencializam quando o material de estudo é um objeto arquitetônico. A arquitetura é uma expressão de poder, visto a necessidade de cooperação e organização de recursos materiais e humanos para sua execução. Sendo assim, é necessário dispor de um poder político para mobilizar e reunir os esforços necessários para as execuções das obras. Nesse estudo, usaremos a arquitetura para entender a estrutura política de Samos através da compreensão destes esforços de gestão de recursos humanos e materiais.
\end{abstract}

1 Esse artigo é resultado de uma pesquisa de Iniciação Científica realizada entre 2017-2019, intitulada "A Monumentalidade como Forma de Afirmação do Poder Tirânico: o caso do Templo de Hera do governo de Polícrates” orientada pela Profa Dra Maria Beatriz Borba Florenzano, no Museu de Arqueologia e Etnologia da USP com apoio financeiro da CNPq.

2 Graduada em História pela Faculdade Filosofia, Letras e Ciências Humanas. aline.porfirio.neves@usp.br 
A pólis, o tirano, o santuário: o uso do culto políade como estratégia de legitimação em Samos

Samos é uma das maiores ilhas do Egeu, tendo $477 \mathrm{~km}$ de extensão, localizada na costa da Ásia Menor, próxima às pólis ${ }^{3}$ de Mileto e Éfeso, e cujo nome empresta à pólis que se situa nesta ilha. A história da ilha é marcada por seu forte comércio marítimo, possível graças à sua localização (SHIPLEY, 2003, p. 5). Uma mostra da grande influência marítima é a imensa quantidade de oferendas de barcos de madeira no Santuário de Hera (BAUMBACH, 2004, p. 163).

Nossa principal fonte escrita sobre a história de Samos é Heródoto, também sendo possível neste encontrar um rico relato sobre o reinado de Polícrates (532-522 a.C. ${ }^{4}$ ). Heródoto justifica esse relato por conta da importância de Samos e da sua arquitetura, como é possível ver no trecho a seguir:

(...) realizaram as três mais grandiosas [obras arquitetônicas] dentre todos os helenos: do cume de uma montanha com cento e cinquenta braças de altura, de lá até embaixo, iniciaram a escavação de uma galeria subterrânea, de duas aberturas, uma de cada lado; o comprimento dessa galeria subterrânea é de sete estádios e sua largura e altura são de oito pés cada uma; por toda essa galeria subterrânea foi escavada outra galeria subterrânea com a profundidade de vinte côvados, e a sua largura é de três pés, através da qual a água, que era proveniente de uma grande fonte, era conduzida por canais construídos ao lado da galeria elevada até a cidade; o arquiteto dessa galeria subterrânea foi o megarense Eupalino, filho de Naustrofo. De fato, esta é uma das três obras; a segunda trata-se de uma parede construída no mar que circunda o porto, sua profundidade é de vinte braças, e o comprimento da parede é maior que dois estádios. E a terceira obra dos sâmios é a construção de um santuário maior do que todos os santuários que nós vimos, cujo primeiro dos seus arquitetos foi Reco, filho de Fileu, um homem nascido na região" ( $H d t$, III, 77-78).

É provável que a primeira forma política adotada por esses jônios tenha sido a monarquia. Nesse sentido entende-se que os reinados tenham durado até o século VIII a. C. Depois disso o governo se dá principalmente pelos geomóroi ${ }^{5}$, sendo este um governo oligár-

3 Nesse artigo, para os termos gregos ainda não traduzidos, iremos usar a forma padronizada do glossário de termos do LABECA, disponível em: http://labeca.mae.usp.br/pt-br/glossary/. No caso de palavras já dicio narizadas, como pólis, não iremos italicizar, usando a forma padrão que consta no Grande Dicionário Houaiss da Língua Portuguesa (2008).

$4 \quad$ Todas as datas nesse texto se referem ao período a.C. (antes de Cristo), mesmo que não seja referido.

5 Literalmente "possuidores de terras". Embora em Atenas os geomóroi fossem fazendeiros e dentro do estamento ateniense inferiores aos eupátridas (Ath. Pol. XIII.2), no caso sâmio a sociedade se encontrava clivada 
quico hereditário formado por donos de terra como já indica o nome que pode ser traduzido como "land-sharers" (SHIPLEY, 1987, p. 39). Essa aristocracia jônica é marcada por ser descendente dos primeiros colonos da ilha. A história política da pólis é fortemente marcada por alternar sempre entre os geomóroi e os tiranos.

\section{POLÍCRATES}

O termo tirano pode ter sido tomado por empréstimo da Lídia, no Oriente, mas o fenômeno não precisou de influência externa (CARTLEDGE, 2002, p. 103). Essencialmente, tirano é aquele que usurpa o poder dos que legalmente teriam esse direito (MOSSÉ, 1984, p. 173). Aristóteles considera os tiranos jônicos como uma particularidade, pois estes surgem em sua maior parte de "famílias notáveis" (Ath. Pol., 1310b, 28-30).

A visão mais clássica enxerga a tirania como uma forma de governo temporária e transitória para a democracia (ANDREWES, 1956, p. 8). Sendo assim, segundo essa leitura, a tirania tinha como função ajustar a pólis para o recebimento de uma forma de governo superior, a democracia. Porém, essa leitura está equivocada, pois cria um paradigma tendo em conta somente a história de Atenas. Ao estudar outras pólis é possível ver que essa estrutura nem sempre se aplica.

Além dessa visão de tirania como uma etapa transitória, Aristóteles via a tirania como a pior forma de governo. Essa interpretação deixa marcas até hoje, como por exemplo: o adjetivo tirânico tem uma grande carga negativa. Essas fontes atenienses apresentam a tirania de forma negativa com o intuito de justificar as escolhas da pólis feitas nos séculos $\mathrm{V}$ e IV (FLORENZANO, 2011, p. 42). Ao estudar tirania é necessário ter em mente que o autor da fonte possui uma interpretação negativa dessa forma de governo.

Uma constante interpretação é a de que o surgimento do tirano se dá em um contexto de crescimento comercial e marítimo. Dessa forma, o tirano surge como representante dos mercados e marinheiros. Porém, existem visões diferentes, como a de Claude Mossé (1984, p. 165) que credita esse surgimento mais ao fortalecimento do poder naval do que ao comércio marítimo. Já para Condilo, a tirania surge em "comunidades prósperas economicamente e isto fez com que houvesse um fortalecimento do poderio naval” (2008, p. 26).

apenas entre os geomóroi e o demo (SHIPLEY, 1987, p. 39). 
A pólis, o tirano, o santuário: o uso do culto políade como estratégia de legitimação em Samos

Além da explicação que relaciona a tirania com o comércio e poderio naval, há ideias que relacionam o surgimento do tirano com as reformas hoplitas que ocorreram em decorrência das inovações técnicas, pois com a utilização do bronze as lanças se tornaram mais leves e capazes de serem usadas em lançamentos. Além dessa mudança técnica houve uma mudança tática, com a utilização do modelo de falange. Nesse modelo os guerreiros ficam numa formação em que o escudo de um protege o outro, sendo necessário que todos andem em harmonia (WHITE, 1955, p. 5).

Considerando a reforma hoplita, o tirano teria surgido como um representante dos guerreiros. Nesse momento é importante lembrar que o exército hoplita era em sua grande parte formado pela classe popular. Contudo, Condilo (2008, p. 29) questiona essa ideia, pois isso é acreditar que os guerreiros da falange possuíam uma consciência de classe.

Tendo explicado e feito considerações às explicações clássicas para o surgimento da tirania, Camila Condilo acredita que esse sistema de governo surgiu com o

\footnotetext{
descontentamento da ordem aristocrática e, em virtude da sua perda de seu domínio econômico, político e religioso, o que levou a disputas internas por poder, e, como uma outra face desta mesma questão, ao problema da justiça e corrupção (CONDILO, 2008, p. 32).
}

Mesmo que consideremos que o tirano não surgiu como representante hoplita, podemos dizer que esse governante se utilizou dessas tropas para tomar o poder (TRABULSI, 1984, p. 77).

O ponto comum dessas teorias é que o tirano surge como uma alternativa para momentos difíceis da polis. Embora o tirano seja caracterizado como dotado de uma sede por poder, ele tende a ter como forma de alcançá-lo o bem-estar local. Uma vez que não possui apoio da aristocracia, ele é forçado a se direcionar a outros grupos sociais para obter a sua legitimidade. Isso se reflete em uma busca por apoio nas classes mais baixas do demo. E é a partir do incentivo de uma espécie de justiça social que ele busca cooptar esse grupo para garantir sua base de poder (CONDILO, 2008, p. 57).

Além da ausência de apoio por parte da aristocracia, o tirano possui outra dificuldade: a ausência de legitimação hereditária. Por chegar ao poder por meio de um golpe no regime aristocrático hereditário, o tirano não consegue se legitimar no poder como sendo parte da dinastia governante (FLORENZANO, 2011, p. 42).

Assim, o tirano tem que buscar se legitimar de outras formas, sendo elas: 1) privilegiando a coletividade, em especial as camadas mais pobres; 2 ) reforma na religião. Conside- 
rando que a religião de âmbito privado é a ancestral e o tirano não consegue se legitimar por via desta, torna-se necessário uma promoção do culto público de deuses políades; 3) uso de regras normativas na sociedade, ao contrário do modelo arbitrário utilizado pela aristocracia (CONDILO, 2008, p. 35).

Uma vez que Polícrates era membro de uma família aristocrática, ele se encaixa na particularidade descrita por Aristóteles. Além disso, Polícrates é filho de Aiakes, também um tirano de Samos. Barron estima que Polícrates nasceu em 570 a.C, aproximadamente. E seu pai, Aiakes I o educou com a intenção de que o sucedesse (1964, p. 211), fato que ocorreu, mas não da forma esperada. Seu governo começa provavelmente em 532 e se encerra em 522 devido ao seu assassinato por Oretes de Sardes.

Mesmo com o desejo de sucessão direta de seu pai, aparentemente entre o governo de Aiakes e de Polícrates houve um intervalo no qual o poder esteve em mãos do geómoros. E por esse motivo foi necessário que Polícrates articulasse um golpe, para isso ele contou com a ajuda dos seus dois irmãos, Pantagnoto e Syloson II. Porém, após conquistar o poder na ilha, Polícrates assassina o primeiro e expulsa o segundo, tornando-se o único senhor de Samos.

Polícrates é tido como o primeiro homem, além de Minos de Cnossos, a querer se tornar rei dos mares e tomar posse de todas as ilhas da Jônia. Em Heródoto, essa visão do tirano sâmio como homem ambicioso é bem aproveitada, não só no modo da sua morte, como também em uma pequena história contada pelo autor ( $H d t$, III, 40-43) na qual o faraó Amásis aconselha Polícrates a tomar cuidado com suas ambiçóes para que os deuses não o punam, de forma que seria aconselhável para o tirano se livrar de algo de extrema importância para ele. O tirano decide então por jogar seu anel ao mar, porém, alguns dias depois os cozi nheiros encontram dentro de um peixe o anel de seu senhor. Dessa forma Polícrates pensa que esse é um sinal divino e volta a acreditar na sua magnitude e nas suas ambiçóes. Por sinal, é sua ambição que o leva a morte, segundo as versões de Heródoto. Essa pequena história serve-nos para perceber a visão que Heródoto tem do tirano como sendo alguém movido por uma ambição pessoal que o leva a realizar ações negativas para a comunidade da pólis. Porém, esse juízo de valor pode ser justificado pelo simples motivo do autor utilizar fontes com visão ateniense que vê a tirania de forma pejorativa em oposição à democracia (CONDILO, 2008, p. 65).

Heródoto apresenta ainda duas versóes para a morte de Polícrates, ambas envolvendo o governador persa Oretes: a primeira narra que a motivação para Oretes capturar Polícrates viria de um comentário que outro governador persa, Mitrobates, fez sobre a cidade - 
A pólis, o tirano, o santuário: o uso do culto políade como estratégia de legitimação em Samos

era tão capturável que um homem, Polícrates, havia tomado o poder dela usando apenas quinze hoplitas. Era uma vergonha para Oretes que essa polis estivesse livre do domínio persa estando situada tão próxima dos seus domínios. Assim, Oretes teria uma motivação baseada na honra, segundo o autor grego ( $H d t$, III, 120). A segunda explicação diz que a motivação de Oretes para se voltar contra Polícrates se devia ao fato do tirano ter feito pouco caso de seu arauto, não lhe dando atenção e mesmo voltando-se as costas contra ele (Hdt, III, 121).

Oretes teria então enviado uma carta a Polícrates, prometendo refúgio em troca de uma grande quantia, suficiente pelo que parece para estabelecer ou reforçar o poderio naval sâmio ( $H d t$, III, 122). Tendo enganado o enviado de Polícrates, Meândrio, o sátrapa persa então consegue com que o tirano sâmio vá até sua corte na Magnésia, mesmo com diversos protestos dos conselheiros e súplicas da filha de Polícrates. Apesar dos avisos, o tirano embarca para encontrar Oretes, porém, é morto pelo persa de maneira que o historiador grego se recusa a descrever. Polícrates é então crucificado na Magnésia em 522 a.C.

É interessante que a narrativa de Heródoto sobre Polícrates segue uma estrutura presente na obra: ascensão e rápida expansão do seu poder até um ápice que leva à uma queda fatal (SILVA, 1995, p. 56); essa estrutura tão presente em histórias pode ter como moral a efemeridade da sorte, como o excesso (a býbris) levou os indivíduos a receberem uma punição divina (CONDILO, 2008, p. 101).

Foi durante o governo de Polícrates que Samos teve seu ápice de prosperidade, tendo o tirano 100 pentekóntoros $^{6}$ e 1000 arqueiros à sua disposição. Essa prosperidade se deve à política de pirataria praticada pelo tirano; porém, a força naval sâmia se dá anteriormente ao governo de Polícrates por conta da importância dada pelos geomóroi ao comércio marítimo.

A prosperidade no período de Polícrates não se deu somente no quesito comercial e marítimo. É possível ver uma valorização das artes. A grande quantidade de achados esculturais de mármores, torsos e fragmentos de estátuas na Via Sacra podem indicar que Samos teve uma importante escola de escultores no sexto século (KYRIELEIS, 1993, p. 118),

era já proverbial entre os gregos, ao tempo de Heródoto, a fama da prosperidade a que o tirano de Samos, no poder desde os anos trinta do séc. VI a.C. tinha guindado a sua ilha; à riqueza, associou-se um requintado mecenatismo, que atraiu à corte artistas célebres, em cujo número figuram os nomes de Anacreonte e Íbico (SILVA, 1995, p. 56). 
Por conta da não aceitação dos governos tirânicos por parte da aristocracia sâmia, foi necessário para Polícrates criar uma base de governo com apoio da classe mais baixa, no demo. E é a partir dessa necessidade que esse artigo pretende dissertar o uso por Polícrates do culto de Hera e da monumentalização do seu templo como forma de criar uma base de apoio para o seu governo.

Se faz necessário ressaltar que o conceito de monumental para a arquitetura é o de um edifício que ultrapassa em escala e elaboração o necessário para o exercício do que se propõe (TRIGGER, 1990, p. 119). Para isto, existe um gasto excessivo que chamamos de consumo conspícuo, o oposto da "lei do mínimo esforço" (HIRATA, 2011, p. 25).

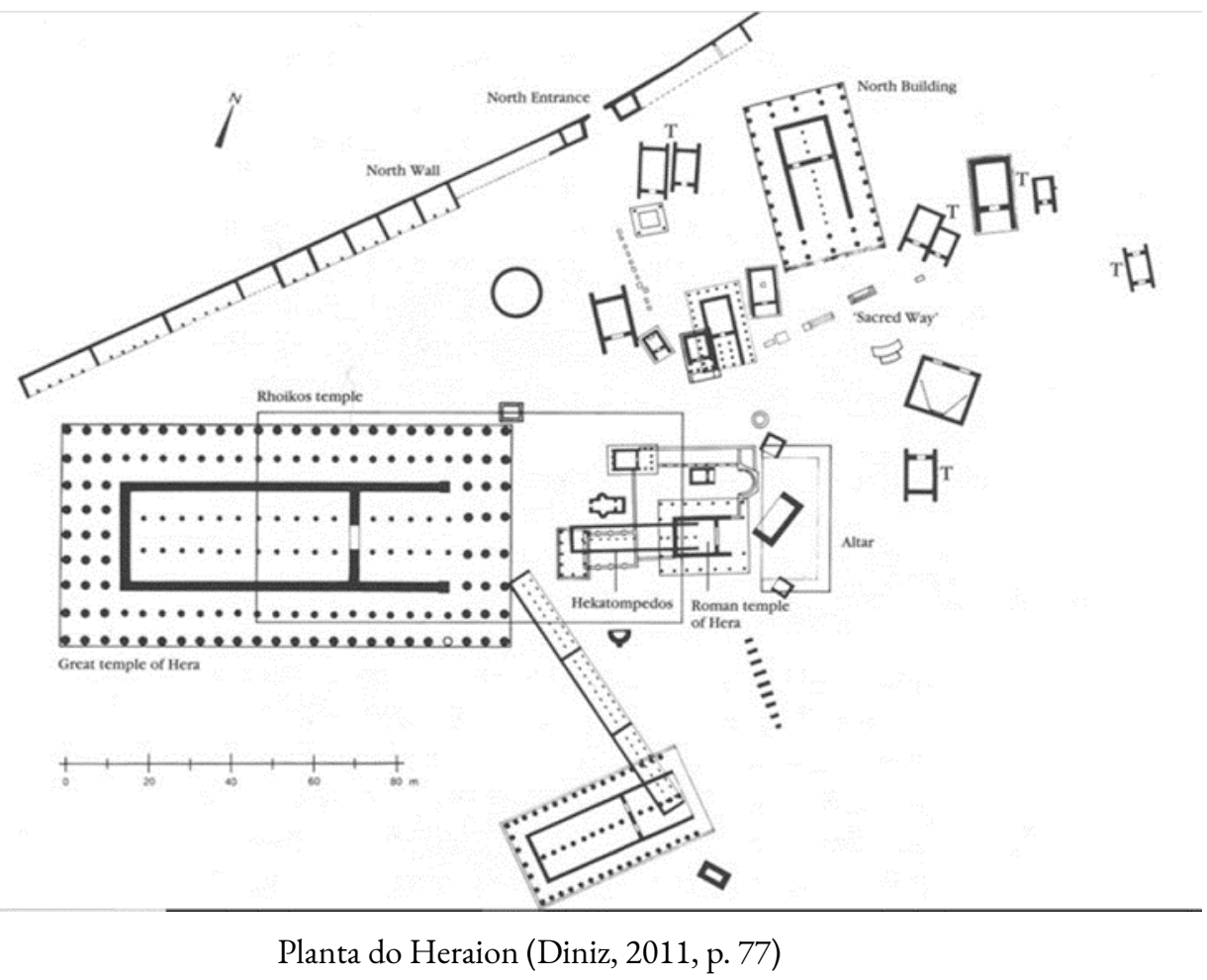

Embora Heródoto considere o Heraion de Samos como o maior dos santuários gregos já visto até então, este recebeu somente uma breve menção por parte de Pausânias. E 
além do grande Templo de Hera e do antigo altar nenhuma das outras estruturas do santuário são citados em fontes antigas.

O santuário está conectando à ásty de Samos por uma via sacra, a distância do território sagrado para a cidade era de quatro quilômetros. O santuário era provavelmente acessado por outros povos via mar antes mesmo na instauração de uma pólis na ilha. O santuário está em uma região de solo fértil e pantanoso (DINIZ, 2011, p. 74-75).

A primeira escavação realizada no santuário foi feita por Kavvadias e Sophoulis em 1820-1822. Porém, nesta etapa não foi possível identificar a extensão do território do santuário, isto só foi descoberto na escavação de 1910-1914, dirigida por Theodor Wiegand (KYRIELEIS, 1993, p. 126).

Graças a essa escavação alemã foi descoberto que o templo se tratava de uma estrutura do período arcaico tardio, com dimensões colossais, possuindo 55 por 108 metros e 155 colunas. Pela análise da fundação foi possível localizar uma edificação anterior com dimensões parecidas, o Templo de Rhoikos. Nessa escavação também foram descobertos os edifícios romanos próximos ao grande templo e um grupo de edifícios ao norte (KYRIELEIS, 1993, p. 127).

Em 1925 ocorreram novas etapas de pesquisa, com direção de Buschor. Estas foram interrompidas em decorrência da Segunda Guerra Mundial (KYRIELEIS, 1993, p. 100), voltando em 1951 com direção de Buschor até 1961, e Homann-Wedeking até 1975. Essas escavações foram importantes para deixar mais claro os períodos mais antigos do santuário.

Foi descoberto que desde a Idade do Bronze havia práticas de culto no santuário (DINIZ, 2011, p. 31). Porém, existe uma au-

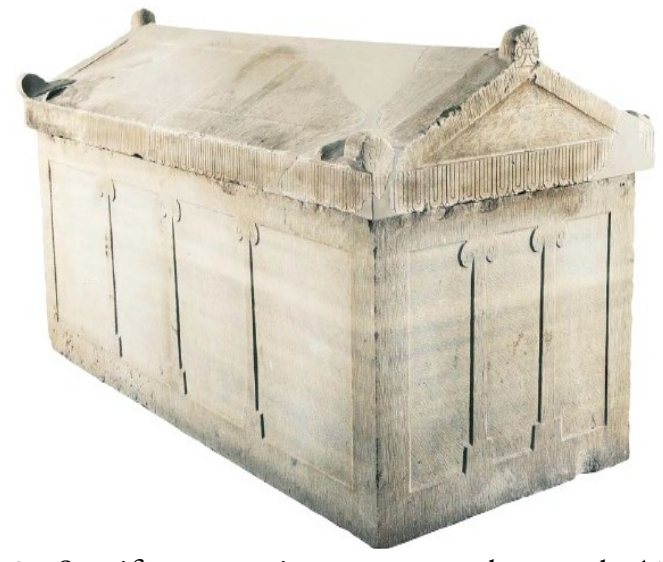

Figura 2 - Sarcófago em mármore, provavelmente de Aiakes, pai de Polícrates (TSAKOS e SOFIANOU, 2012, p. 215).

$7 \quad$ Embora o conceito de polis tenha se imbricado com a ideia de uma cidade, a polis é uma entidade política, e não uma designação espacial. Desta maneira, quando usamos o termo polis, queremos nos referir à enti dade política e todo o território sob seu controle, que se divide em duas áreas conforme a natureza da ocupação do espaço: a astý, o núcleo urbano, e a khóra, porção de ocupação da hinterlândia (LONIS, 1994, p. 93-108). 
sência de material cerâmico que identificasse o culto durante o período submicênico (sécs. XII-XI a.C.). Segundo Diniz (2011, p. 31), é possível que o culto tenha continuado, porém, sem deixar evidências. O primeiro sinal do Templo de Hera data do século X, em forma de um altar. É possível identificar duas substituições e ampliações desse altar, uma no século IX e outra no VIII. Esta última conta com uma base para imagem de culto situada a oeste. Na segunda metade do VIII houve mais uma renovação do altar e o acréscimo de naiskoi ${ }^{8}$. Nesse momento a estrutura do altar possuía 304 metros (KYRIELEIS, 1993, p. 116).

No século VII, o primeiro templo do santuário foi construído, um bekatômpedon', juntamente com a construção de uma stoa, ao sul. E como meio de acesso da ásty para o santuário é realizada a construção da Via Sacra. Essas duas construçóes foram promovidas pelo estado sâmio para que houvesse uma apropriação do santuário, dessa forma criando uma identidade para a pólis de Samos (DINIZ, 2011, p. 105).

Não existem vestígios materiais que comprovem a existência de uma via de acesso da ásty para o santuário anterior à Via Sacra. Por conta disso, embora não fosse um santuário pan-helênico, Diniz (2011, p. 74) considera a possibilidade de no princípio o Heraion ter sido utilizado pelas comunidades vizinhas, com acesso via mar. Dessa forma, a autora acredita que a construção do bekatômpedon e da Via Sacra foi uma forma da pólis se apropriar do santuário. Essa apropriação poderia ter como objetivo fortificar a pólis, dado que esse era um momento importante para Samos por conta do crescimento dos seus contatos no Egeu.

Em 570 temos o primeiro indício de um edifício monumental, construído para substituir o bekatômpedon. Esse edifício é chamado de templo de Theodoros e Rhoikos, seus arquitetos, sendo ele um díptero de extensão monumental, já com estrutura de ordem jônica. No túmulo de Aiakes, pai de Polícrates, é possível vermos uma suposta representação do que seria o Templo nesse momento, com a ordem jônica aparente (figura 2).

Nesse mesmo período também foram realizadas as seguintes obras dentro do santuário de Hera: a extensão do témeno; a construção de um altar monumental a oeste; adição de mais dois naiskoi; a construção de um edifício ao norte, que se tem como sendo possivelmente um templo; e por último a extensão da Via Sacra para a ágora dentro da ásty sâmia, conectando o centro cívico com o centro religioso da pólis (KYRIELEIS, 1993, p. 127).

8 Diminutivo de naós; pequeno templo, pequeno santuário (Fonte: Glossário do LABECA, disponível em: http://labeca.mae.usp.br/pt-br/glossary/).

9 De cem pés de extensão; qualquer templo antigo com essa medida (Fonte: Glossário do LABECA, disponível em: http://labeca.mae.usp.br/pt-br/glossary/). 
A pólis, o tirano, o santuário: o uso do culto políade como estratégia de legitimação em Samos

Em torno de 550 a.C., o Templo de Rhoikos e Theodoros teve sua estrutura abalada devido às condiçốes geográficas do local, um solo pantanoso que não estabiliza muito bem as construçôes. E é como um substituto desse templo de Rhoikos que Polícrates, em 530 a.C., começa a construção do Grande Templo de Hera, 40 metros mais a oeste do que o antigo templo (KYRIELEIS, 1993, p. 100). Nesse período também são erigidos ao sul dois novos templos. Polícrates não viu a finalização da construção do seu grande templo, tendo morrido oito anos depois, em 522 a.C.

No século V ocorre a decadência de Samos e a emergência de Atenas como "senhora do Egeu" (DINIZ, 2011, p. 32). Por decorrência disso, em 490 a.C. a construção do Grande Templo é cessada. Esse é um momento difícil para o santuário de Samos, pois segundo Kyrieleis (1993, p. 105), só foram encontradas 51 oferendas votivas desse período no santuário.

O que vemos hoje é somente uma coluna restante, mas esta é da construção romana, que também não foi concluída. Dada essa interrupção da construção, a estátua de culto foi levada para um templo a oeste. Este templo esteve de pé até o século IV d. C. No século V uma igreja cristã foi construída ao lado do templo romano, sendo constituída de spolia desse (KYRIELEIS, 1993, p. 135).

A categoria "grego" é pouco homogênea, sendo dentre as características comuns entre os gregos, duas delas a língua e a religião. Sendo assim é possível dizer que a religião é um agente responsável pela categoria de “gregos”. Porém, é necessário ter em mente que mesmo a religião sendo a mesma, os deuses adquirirão características diferentes a depender da região de culto.

Isso acontece com Hera, deusa políade de Samos. Quando pensamos na deusa é comum sempre a associar com o seu esposo Zeus, com seu forte ciúme e sua característica de deusa vingativa. Essas características são heranças da literatura homérica. Porém, precisamos nos desvencilhar um pouco dessas características de deusa do Panteão e encontrar a partir das evidências de culto as características de Hera, deusa políade de Samos.

Segundo a mitologia sâmia, Hera nasceu na ilha, embaixo de um pimenteiro-silvestre (KYRIELEIS, 1993, p. 106-107) e, por conta desse mito é considerada a deusa patrona 
de Samos. Uma vez por ano acontecia na ilha a Toneia, festival onde a imagem de Hera era envolta em ramos de pimenteiro-silvestre e levada ao mar para receber um banho.

Uma boa fonte para o estudo do culto de Hera são as oferendas votivas encontradas no santuário. Segundo Kyrieleis (1993, p. 112), foram encontradas em torno de 40 miniaturas de barco de madeira, todas elas com o mesmo formato e características. $\mathrm{O}$ autor acredita que esses barcos foram feitos exclusivamente para o Heraion e eram um objeto utilizado em rituais. A exclusividade pressuposta por Kyrieleis vem do fato que o barquinho poderia ter sido feito de outro material, como bronze, e pela ausência desse tipo de barco em outros lugares. Porém, acreditamos que nesse momento se faz importante lembrar que poucos sítios são capazes de conservar madeira, então pode ser que esse objeto não fosse exclusivo de Samos, mas só sobreviveu aos tempos atuais em Samos devido ao solo pantanoso do santuário, que tem a capacidade de conservar materiais orgânicos como a madeira.

A presença desses barcos no santuário, a disposição do altar virado para o mar, conjuntamente com a tradição de banhar a imagem da deusa no mar, indicam uma forte ligação da deusa com o mar para os sâmios. O que é conveniente, já que por um grande período os sâmios tiveram uma poderosa frota marítima e um comércio marítimo bem presente.

Outro elemento frequentemente encontrado no santuário são sementes de papoula e romã, além de representações de romã em cerâmica. A romã, fruta com muitas sementes, nos remete à fertilidade. Outro elemento do santuário que pode remeter à fertilidade é o próprio local. Como já dito, o Heraion está em local de solo pantanoso, condição também ligada à fertilidade, sendo então essa mais uma característica da deusa Hera políade de Samos.

A análise da quantidade das oferendas votivas presentes no santuário possibilita levantar considerações sobre os frequentadores do local sagrado e, dessa forma, sobre as características e funções do culto realizados em homenagem à deusa. Para tal, iremos utilizar dois principais tipos de oferendas, miniaturas de cavalo e de gado. Assim como é apontado por Diniz (2011, p. 34), o cavalo também foi para os gregos um animal de luxo, andar de cavalo era uma atividade vol-

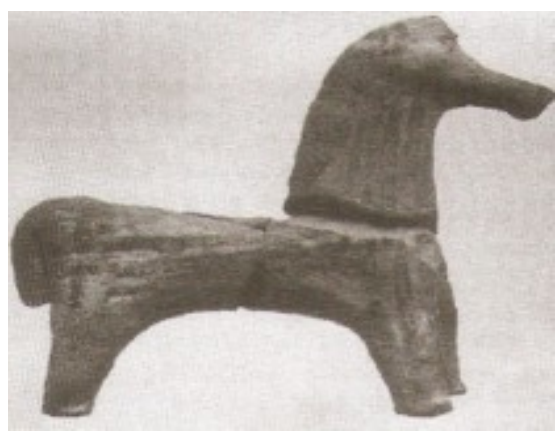

Figura 3 - Miniatura de cavalo encontrada no Heraion (Kyreleis, 1993). tada para a aristocracia. Já o gado é ligado à vida do campo ${ }^{10}$. Antes de apresentar a análise

10 Faz-se necessário aqui uma ressalva: tanto o cavalo quanto o gado são animais ligados à deusa Hera. Homero descreve a deusa como tendo "olhos de vaca" (Il. 1.494). 
A pólis, o tirano, o santuário: o uso do culto políade como estratégia de legitimação em Samos

quantitativa é importante dizer que o cavalo também é um elemento bastante presente no que se diz respeito à Hera em Samos, não há em outro santuário uma presença tão grande de arreios.

As representaçôes de gado foram predominantes no santuário entre os séculos IX e VIII, porém, a partir do século VIII já começa a haver uma predominância maior dos cavalos, principalmente a partir de 750, e com isso, consequentemente, há uma queda brusca nas miniaturas de gado. Segundo Diniz (2011, p. 34-35), há novamente uma queda de oferendas vindas da aristocracia no santuário sâmio. A autora supóe que essa queda pode ser indício de que a aristocracia não dá mais importância para a ostentação de oferendas ou pode indicar falta de recursos. Porém, imaginamos que outra possibilidade de interpretação para essa queda durante o reinado de Polícrates é a associação do tirano com o santuário, dessa forma a aristo cracia, público ofertante das miniaturas de cavalo, como já explicado anteriormente, não vê mais o local como adequado para as suas oferendas, o que justifica a diminuição da quantidade dessas oferendas no santuário.

Importante lembrar que quando os governos tirânicos assumem o poder tornamse responsáveis pelo culto. Dessa forma o tirano tem a chance de fortalecer a religião da deusa políade, já que para ele não convém o culto privado de antepassados, prática comum dentro da aristocracia. Podemos então concluir que a decisão de Polícrates de monumentalizar o Templo de Hera não alterou somente a arquitetura, mas também alterou o público que frequentava o santuário, como é possível ver nas oferendas.

A monumentalização do Templo não só criava a imagem de um governante preocupado com a religião e o culto da pólis, mas também era uma forma de escancarar que Polícrates tinha poder suficiente para cuidar da gestão de mão de obra e recursos da realização de uma obra monumental. Exibindo o consumo conspícuo, tornando este um local de manifestação de poder.

A decisão de Polícrates por monumentalizar o Templo de Hera fazia parte de uma estratégia para a criação da sua base de poder. Assim, Polícrates utilizou da religião de forma política. Para Trabulsi (1984, p. 78), é comum utilizar o político e o ideológico de forma conjunta, ainda mais no período Arcaico quando não há uma nítida separação entre essas 
duas esferas. Em oposição à individualidade aristocrática, as obras arquitetônicas promovidas por Polícrates o colocou como elemento de construção da identidade da pólis.

Dessa forma, concluímos que Polícrates, ainda que de maneira não-original, promoveu a monumentalização do Templo de Hera como forma de demonstrar e afirmar seu poder. Porém, o plano para a criação de base de governo de Polícrates não conta só com exibição do consumo conspícuo exigido para a realização de um edifício com dimensões tão monumentais. Ele conta também com a imagem do tirano associada com o templo e com o culto de Hera, principalmente se considerarmos o caráter políade da deusa, e que se reflete na mudança de elementos votivos no santuário associados a uma mudança de culto durante o governo do tirano. Dessa forma, Polícrates se coloca como uma figura que está presente no templo, assim como a deusa e, ao promover a construção e renovação do seu santuário e de seu culto, Polícrates se apresenta como um renovador não apenas do edifício, mas de toda a pólis. 
A pólis, o tirano, o santuário: o uso do culto políade como estratégia de legitimação em Samos

REFERÊNCIAS BIBLIOGRÁFICAS

ANDREWES, A. The Greek Tyrants. London: Hutchinson, 1956.

ARISTÓTELES. Politica. Tradução de António Campelo Amaral e Carlos de Carvalho Gomes. Lisboa: Vega, 1998.

BARRON, J. P. The Sixth-Century Tyranny at Samos. The Classical Quarterly, v. 14, n. 2, p. 210-229, 1964.

BAUMBACH, J. The Significance of Votive Offerings in Selected Hera Sanctuaries in the Peloponese, Ionia and Western Greece. BAR International Series 1249. Oxford: Archaeopress, 2004.

CARTLEDGE, P. História Ilustrada da Grécia Antiga. Rio de Janeiro: Ediouro, 2002.

CONDILO, C. D. S. Heródoto, as tiranias e o pensamento politico nas Histórias. 2008. Dissertação (Mestrado em História Social), Departamento de História da Faculdade de Filosofia, Letras e Ciências Humanas, Universidade de São Paulo, São Paulo, 2008.

DINIZ, S. Os Santuários de Hera enquanto elementos do espaço poliade. 2011. 195f. Dissertação (Mestrado em Arqueologia) - Museu de Arqueologia e Etnologia, Universidade de São Paulo, São Paulo, 2011.

FLORENZANO, M. B. B. Construindo o Helenismo: o tirano e a monumentalização urbanística da pólis grega. In: ALDROVANDI, C. E. V.; KORMIKIARI, M. C. N.; HIRATA, E. F. V. Estudos sobre o espaço na Antiguidade. São Paulo: EDUSP, 2011, p. 41-56.

HERODOTO. Histórias. Tradução de Maria Aparecida de Oliveira Silva. São Paulo: Edipro, 2017.

KYRIELEIS, H. The Heraion at Samos. In: MARINATOS, N.; HÄGG, R. Greek Santuaries. London: Routledge, 1993, p. 125-153. 
LÉVÊQUE, P. La personnalité d'Héra. In: GENIÈRE, J. D. L. HÉRA. IMAGES, ESPACES, CULTES. Naples: Publications du Centre Jean Bérard, 1997, p. 267-270.

LONIS, R. La cité dans le monde grec. Structures, fonctionnement, contradictions. Paris: Nathan Université, p. 93-108, 1994.

MOSSÉ, C. A Grécia Arcaica de Homero a Ésquilo. Tradução de Emanoel Lourenço Godinho. Lisboa: Edições 70, 1984.

PAUSANIAS. Descripción de Grecia. Tradução de Maria Cruz Herrero Ingelmo. Madrid: Gredos, v. I - X, 1994.

SHIPLEY, G. A History of Samos. New York: Oxford University Press, 1987.

SILVA, M. D. F. A História de Polícrates de Samos. HVMANITAS, v. 47, p. 55-70, 1995.

TRABULSI, J. A. D. Crise social, tirania e difusão do dionisismo na Grécia arcaica. Revista de História, v. 116, p. 75-104, 1984.

TRIGGER, B. G. Monumental Architecture: A Thermodynamic Explanation of Symbolic Behaviour. World Archaelogy, v. 22, n. 2, p. 119-132, 1990.

TSAKOS, L; VIGLAKI-SOFIANOU, M. Samos: The Archaeological Museums. Athenas: Olkos, 2012.

\section{IMAGENS}

Imagem 1: Planta do Heraion (Diniz, 2011, p. 77)

Imagem 2: Sarcófago em mármore, provavelmente de Aiakes, pai de Polícrates (TSAKOS e SOFIANOU, 2012, p. 215).

Imagem 3: Miniatura de cavalo encontrada no Heraion (Kyreleis, 1993). 